\title{
Selection and Evaluation of Materials for Solar Heater Boxes and Their Capacity in Trapping Solar Energy
}

\author{
${ }^{1}$ Ragaa Mohammed Elbashier Elhadaa, ${ }^{2}$ Rita Muhamad Awang, ${ }^{2}$ Dzolkhifli \\ Omar, ${ }^{3}$ Uma Rani Sinniah and ${ }^{4}$ Ionel Vaieriu Grozescu \\ ${ }^{l}$ Department of Plant Protection, Faculty of Agricultural Studies,Sudan Universityof Science and Technology, \\ ${ }^{2}$ Department of Plant Protection, Faculty of Agriculture, University Putra Malaysia, 43400 UPM, Serdang \\ ${ }^{3}$ Department of Crop Science, Faculty of Agriculture,University Putra Malaysia, 43400 UPM, Serdang. \\ ${ }^{4}$ Faculty of Engineering, SEG: University College, Kota damansara
}

\begin{abstract}
The selection and evaluation of solar heaters for trapping and using solar energy to disinfest legume grains are described. The effectiveness of five materials (cardboard, plywood, Perspex timber and metal) in collecting heat as temperature from the sun was investigated. two different linings materials were used to coat solar heater boxes aluminum foil, and black paint. Solar heater boxes were covered with clear plastic to trap solar radiation. Cardboard and plywood were the best materials to construct the solar heater boxes as they trap and retained more heat due to their high thermal diffusivity compared to perspex and timber solar heater boxes. In addition, these materials are cheaper and easier to handle compared to metal. It was also concluded that, aluminum foils combined with black paint was the best lining than aluminum foil or black paint used separately. The effect of seed depth on solar energy collection inside cardboard and plywood solar heater boxes was also evaluated.Temperatures trapped in cardboard solar heater boxes with $7 \mathrm{~kg}$ of seeds was $13.9 \%$ higher than temperatures trapped in plywood solar heater boxes. Therefore, cardboard solar heater boxes were better than plywood solar heater boxes.
\end{abstract}

Keywards: Vigna angularis, solar heaters, seed disinfestations, seed depth

\section{Introduction}

Malaysia is in the tropical region therefore solar radiation is quite high and hence it is suitable to use solar power as a safer alternative energy source. The availability of sun light in Malaysia is more than $10 \mathrm{~h}$ daily and it is possible to have about $6 \mathrm{~h}$ of direct sun light with irradiation of $800 \mathrm{~W} / \mathrm{m}^{2}$ and $1000 \mathrm{~W} / \mathrm{m}^{2}$ (Amin et al., 2009). Limited studies have been conducted on the use solar energy to control insects although the approach has potential for long-term storage. Work on solar heat treatments of commodities of food has mostly targeted bruchid pests of seeds using a variety of solar heating methods (Murdock and Shade, 1991; Kich et al., 1992; Ntoukam et al., 1997; Chuahan and Ghaffar, 2002; Mekasha et al., 2006). Solar energy is one of the cleanest energy sources that does not add to the global warming. In addition, it is available in abundance with minimum environmental and ecological hazards associated with its production and use (Solange et al., 2011). Heat disinfestation is a perfect system and the uniqueness of this system are secure and simple to use; moderately rapid, successful, saves grain quality with lowest adverse impact on the environment; flexible, and appropriate for personal grain lots (Qaisran and Banks, 2000). Utilization of heat continues to be one of the best alternatives as it is easy, fast, and offers residue-free disinfestations of grain. This method could be widely used in the grain industry in the near future and its use might be integrated with other methods to provide quality grain protection (Banks, 1998). Limited research has been conducted on solar heater boxes. Mekasha et al (2006) used metal solar heater boxes to evaluate their capacity in trapping solar energy for one kilogram samples of adzuki bean seeds. Metal solar heater boxes are however, heavy and relatively expensive. Therefore, the objectives of the present study was to select and evaluate the capability of other materials with different thermal properties for use in solar heater boxes for trapping solar energy and also design heater boxes that can handle larger seed samples.

\subsection{Materials}

\section{Materials and Methods}

The solar heater boxes were designed in a conical shape with $118^{\circ}$ as base angle. The upper open sides of the boxes were $50 \times 50 \mathrm{~cm}$ with a perpendicular height of $50 \mathrm{~cm}$ (Fig 1). 


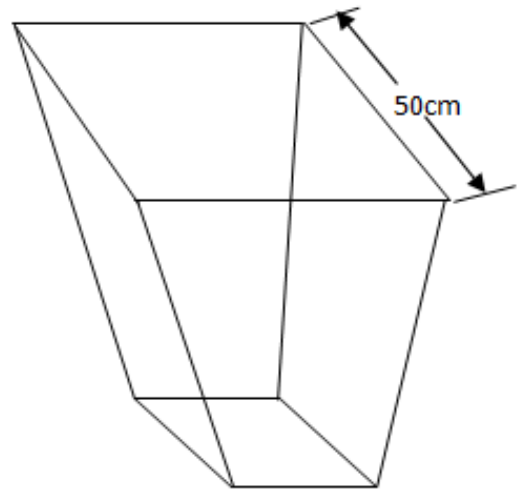

(a)

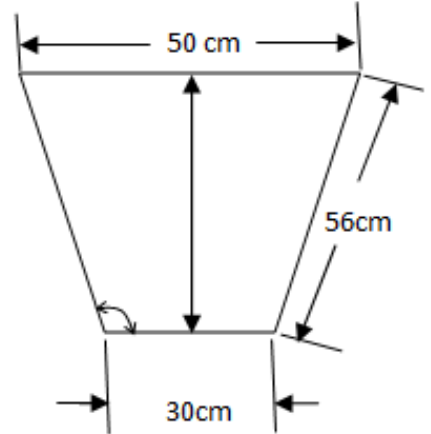

(b)

Fig 1: Design of solar heater boxes (a) Dimension of the solar heater boxes, (b) Base angle and the perpendicular height of solar heater boxes

This design has been tested by Mekasha et al (2006) to be the best design in trapping solar energy (using metal solar heater boxes). The same design was deemed suitable for the present study, but different materials were tested for their capacity to trapping solar energy. The wall of the solar heater boxes were basically constructed of five different materials of variable thickness: perspex (3 mm), cardboard (2 mm), plywood (9 $\mathrm{mm})$, timber $(9 \mathrm{~mm})$ and metal $(1.2 \mathrm{~mm})$. The inside wall of the boxes were coated with one of two materials (aluminum foil or black paint). The outside and base of boxes were insulated by a $10 \mathrm{~mm}$ thick polystyrene sheet to reduce heat loss due to convection and conduction. The adzuki bean seeds in fabric bags were placed on square shaped tray $(38 \times 38 \mathrm{~cm})$ in the middle of the solar heater boxes. The solar heater boxes were covered with glazing clear plastic sheet of $0.15 \mathrm{~mm}$ thickness to trap solar radiation. There were three types of boxes: Type 1 - the inside wall of the box was coated with black paint, Type 2 - the inside wall of the box was coated with aluminum foil, and Type 3 - the inside wall of the box was coated with a layer of aluminum foil combined with black paint.

Aluminum foils were used as a good reflector for solar radiation, while black paint is a good absorber. However, in this study box walls were first painted black and then coated with aluminum foil. Therefore, black paint was not used as absorber, but to reduce heat loss. For polystyrene and air the thermal conductivity was very low, and therefore they can be considered as insulating materials. Polystyrene is a good insulator as it contained bubbles filled with air that are able to reduce heat loss. Temperatures were measured with three "Type J" thermocouples connected to "Intech Micro2100-A16" data logger. The between seed temperature was detected using two $5 \mathrm{~mm}$ diameter thermocouples (Fig. 2a). This temperature is useful since it affects adults and eggs of insects outside the seed. The within seed temperature was measured using one $1 \mathrm{~mm}$ diameter thermocouple (Fig. 2b). This temperature is relevant because it affects the developmental stages of the insects. Thermocouples of $1 \mathrm{~mm}$ and $5 \mathrm{~mm}$ were placed outside at about $15 \mathrm{~cm}$ above the ground to detect ambient temperature.

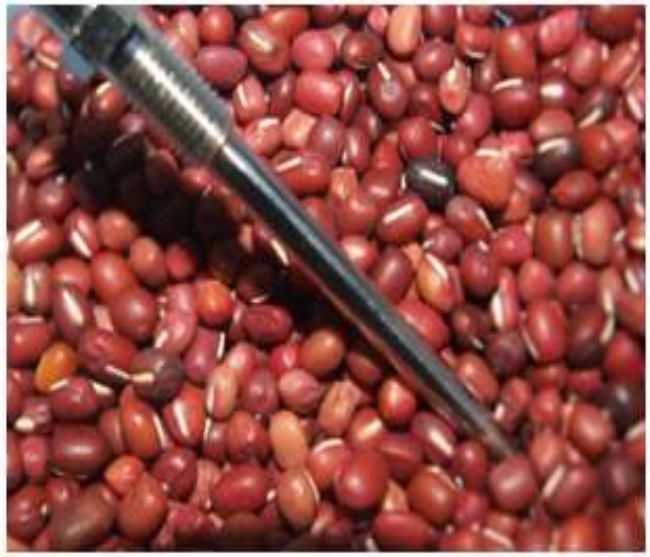

(a) Between seeds

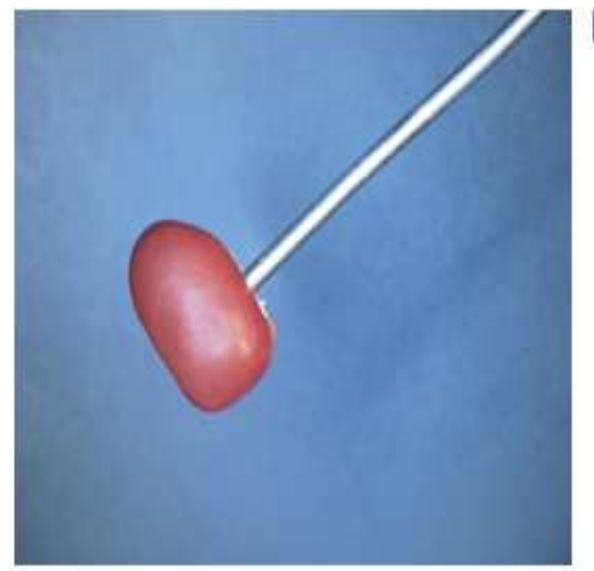

(b) Within seed

Fig. 2: Temperature measurements with thermocouples: (a) between seeds, (b) within seeds 


\subsection{Methodology}

Two experiments were conducted to evaluate the trapping capacity of solar heater boxes:

\subsubsection{Experiment 1: Evaluation of solar energy trapping capacity of different solar heater boxes}

Five different solar heater boxes were used (cardboard, plywood, perspex, timber and metal). The interior sides of solar heater boxes that face the sun were glued with three different linings: first, aluminum foil; second, black paint and third, a combination of aluminum foil and black paint. The outside and bases of boxes were insulated by fixing $10 \mathrm{~mm}$ thick polystyrene. One kilogram seeds of adzuki bean $V$. angularis were placed in a fabric bag on the tray made of the same materials as the boxes. The trays were provided with holes to allow temperature penetration from different directions. The tray was fixed in the middle of the perpendicular height of each box to allow for heating from all directions. The boxes were then covered with $0.15 \mathrm{~mm}$ thick clear plastic sheet as glazing material. The plastic cover was fixed tight using angled-wood frame, except in the metal solar heater boxes which were covered with metal frames. The treatments were applied for five hours, 10:00 pm to $3: 00 \mathrm{pm}$.

\subsubsection{Experiment 2: Effect of seed depth on temperatures trapped by solar heater boxes}

Based on results of experiment 1, cardboard and plywood solar heater boxes were selected for this experiment to evaluate the effect of five different seed layer thickness on the capacity of the solar heater boxes in trapping solar energy. The boxes were lined with black paint combined with aluminum foil as this was selected as better lining material in retaining heat inside the solar heater boxes. Varying amount of seeds namely one, three, five, seven and nine kilograms of adzuki bean seeds were used. The seeds were placed in a perspex tray; (the $2 \mathrm{~mm}$ thick perspex tray is known to transmit $92 \%$ of the light that pass through it) in the middle of the perpendicular height of each box. The solar heater boxes were then covered with $0.15 \mathrm{~mm}$ thick clear plastic sheet as glazing material. The treatments were exposed to solar heat for two hours, from 1:00 pm to 3:00 pm. Between seed temperatures and the ambient temperature were detected as explained in section 3.2.2. In this experiment three thermocouples were placed between the seeds at different location in the box to measure the average temperature inside the solar heater boxes.

\section{Data analysis}

Statistical Analysis Software (SAS) was used to analyze the data using analysis of variance (ANOVA) procedure for a two-factor experiment. Duncan Multiple Range Test (DMRT) was used for means comparison in both experiments. Both experiments were carried out using a randomized complete block design (RCBD) with six replications.

\section{Results and discussion}

\subsection{Experiment 1. Evaluation of solar energy trapping capacity of different solar heater boxes materials}

In boxes coated with black paint layer, it was observed that with the beginning of exposure time the between seed temperatures increased as time increased (Fig3); however towards the end of the exposure time temperatures decreased. Temperatures in all solar heater boxes exceeded that of the ambient air. Relatively high mean temperatures of 62.0 and $60.5{ }^{\circ} \mathrm{C}$ were obtained in metal and Perspex solar heater boxes after 240 minutes of exposure respectively.

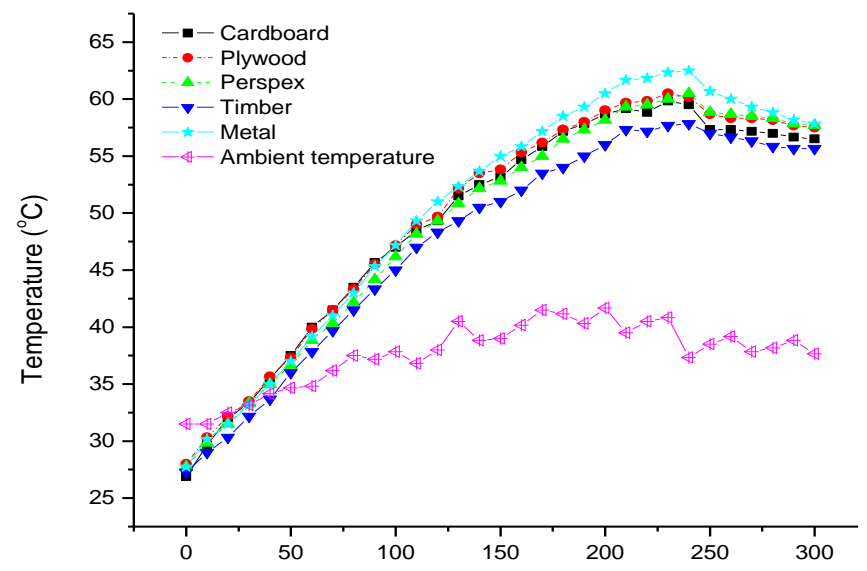

Fig. 3: Temperature profile outside adzuki bean seeds in solar heater boxes lined by a layer of black paint 
In cardboard and plywood solar heater boxes the temperatures increased to 59.8 and $60.5{ }^{\circ} \mathrm{C}$ respectively, after 230 minutes of exposure. Metal solar heater boxes trapped temperature $3.7 \%$ higher than the temperature trapped in cardboard solar heater boxes and $2.5 \%$ higher than the temperature trapped in plywood solar heater boxes. Cardboard solar heater boxes trapped temperature 1.2\% lower than temperature trapped in Perspex solar heater boxes. Between seed temperatures over five hours in the solar heater boxes glued with aluminum foil are represented in Fig. 4. Results showed that temperatures increased with increase in exposure time. Observations demonstrated that ambient temperatures tended to fluctuate during the two hours of exposure due to periodic cloud cover. However, temperatures in the solar heater boxes remained stable during the same period.

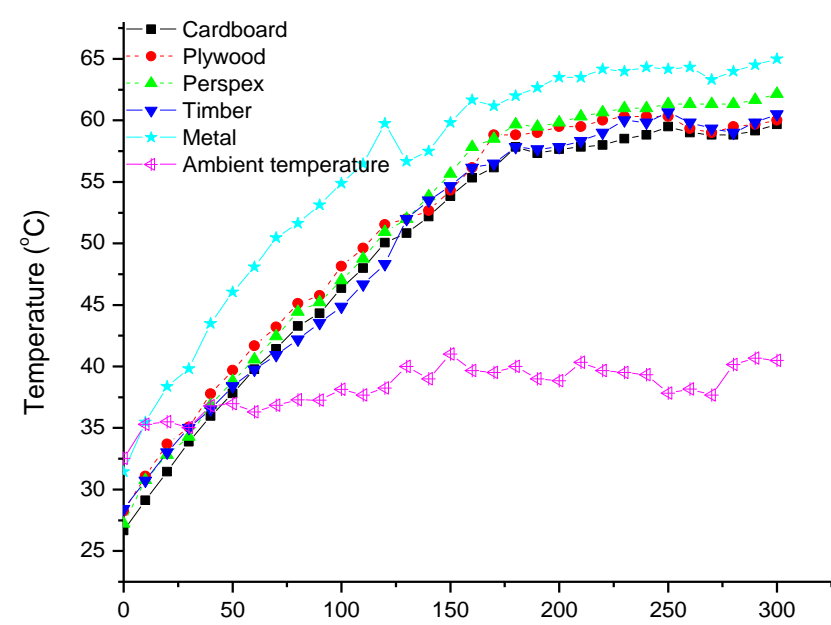

Fig. 4: temperature profile outside adzuki bean seeds in solar heater boxes lines by a layer of aluminum foil

The highest mean of temperature was trapped in metal solar heater boxes, which was $8.9 \%$ and $7.8 \%$ higher than temperatures trapped in cardboard and plywood solar heater boxes, respectively. Cardboard and plywood solar heater boxes trapped $4 \%$ and $3.1 \%$ lower than temperature trapped in perspex solar heater boxes, while timber solar heater boxes trapped $6.9 \%$ and $2.7 \%$ lower temperatues than metal and perspex solar heater boxes, respectively.Between seed temperature increments over five hours in solar heater boxes coated with layer of a combination of black paint and aluminum foil are presented in Fig. 5. The results showed that high mean temperatures of $64.0,63.8,63.0,58.8$ and $58.7{ }^{\circ} \mathrm{C}$ were trapped in Perspex, metal, cardboard, plywood, and timber solar heater boxes respectively, after 250 minutes of exposure compared to the $37.5^{\circ} \mathrm{C}$ ambient temperature. Temperatures trapped in metal solar heater boxes were $1.3 \%$ higher than temperatures trapped in cardboard solar heater boxes. The temperatures trapped in plywood and timber solar heater boxes were $6.7 \%$ and $6.8 \%$ lower than the temperatures trapped in cardboard solar heater boxes.

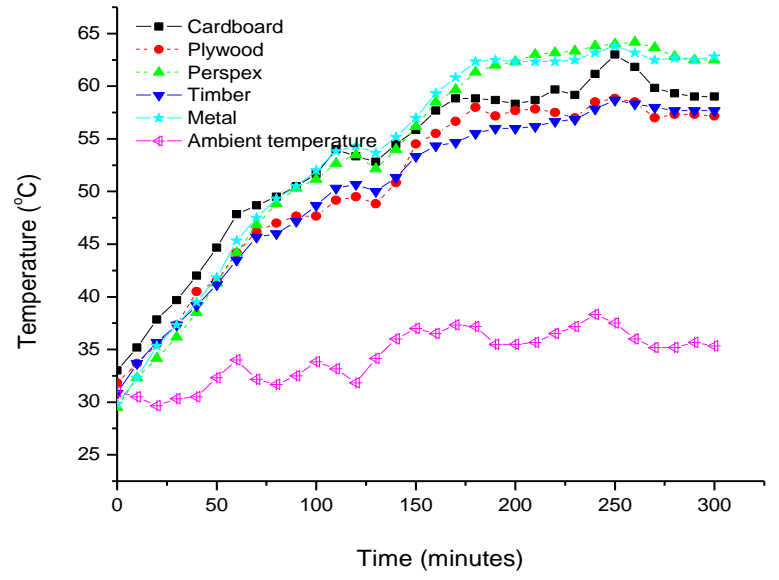


Fig. 5. Temperature profiles outside adzuki bean seeds in solar heater boxes lined with aluminum foil combined with black paint

Within seed temperatures obtained during five hours in solar heater boxes coated with black paint are presented in Fig 6. The trend in heat generated was similar to that in Fig 3. At the beginning temperatures increased as time increased, while at the end of exposure time temperatures decreased.

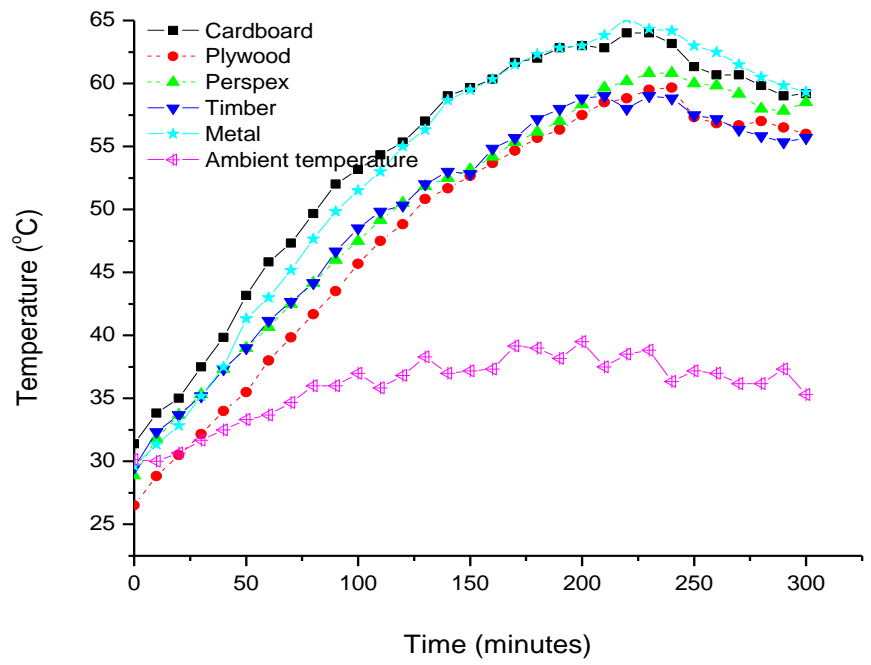

Fig. 6: Temperature profile inside adzuki bean seeds in solar heater boxes using a layer of black paint as lining

Highest temperature was obtained in metal solar heater boxes $\left(65.1^{\circ} \mathrm{C}\right)$ followed by cardboard solar heater boxes $\left(64.0^{\circ} \mathrm{C}\right)$ after 220 minutes of exposure. While temperatures trapped in Perspex and plywood solar heater boxes were 60.8 and $59.8{ }^{\circ} \mathrm{C}$, respectively at 240 minutes of exposure. Temperatures trapped in metal solar heater boxes were 7.1 and $8.9 \%$ higher than temperatures trapped in Perspex and plywood solar heater boxes, respectively. While cardboard solar heater boxes trapped 5.3 and $7 \%$ higher temperatures than Perspex and plywood solar heater boxes, respectively. Timber solar heater boxes trapped the lowest mean temperature which was 9.8 and $8.1 \%$ lower than temperatures trapped in metal and cardboard solar heater boxes, respectively.Within seed temperatures over five hours in solar heater boxes coated with aluminum foil are presented in Fig 7. The trend in heat generated was similar to Fig 4. High mean temperatures of 64.1, 61.1, 60.1, 60.0, and $59.5{ }^{\circ} \mathrm{C}$ were obtained in metal, Perspex, plywood, timber and cardboard solar heater boxes, respectively at the end of exposure time. It was observed that higher temperatures were obtained in metal solar heater boxes compared to others solar heater boxes.

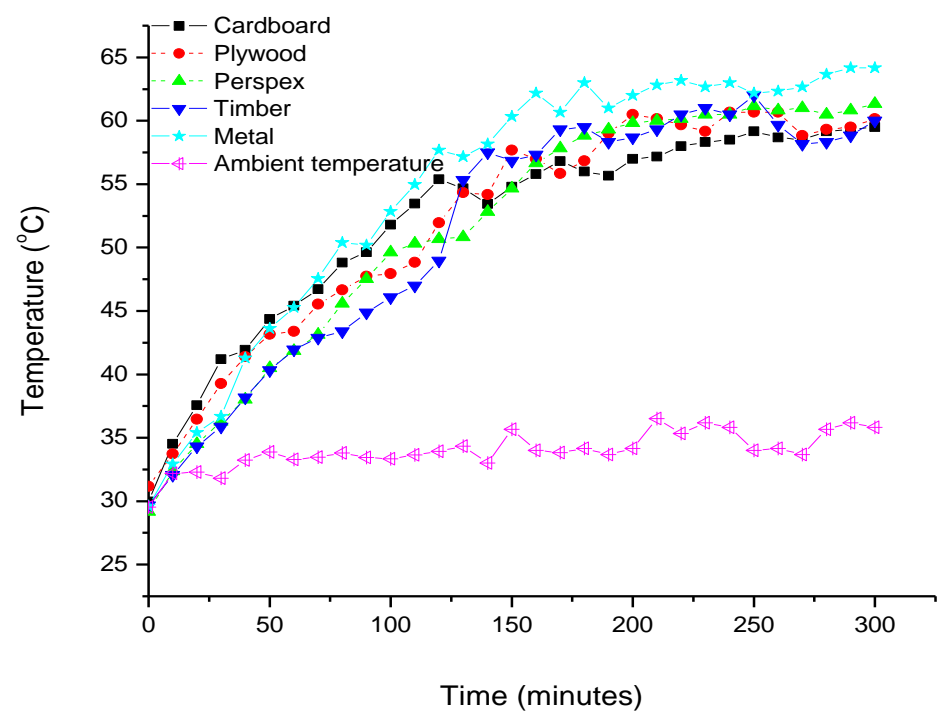


Fig 7: Temperature profiles inside adzuki bean seeds in solar heater boxes using a layer of aluminum foil aslining

The trend in within seed temperatures over five hours of exposure in solar heater boxes coated with a layer of black paint combined with aluminum foil are presented in Fig 8. It was observed that the temperature trend was more stable than in boxes lined with black paint or aluminum foil separately. Temperature means inside seeds were increased to $64.8,63.0,61.0$ and $57.0^{\circ} \mathrm{C}$ in Perspex, metal, cardboard, and plywood solar heater boxes, respectively, after 250 minutes of exposure. The lowest mean temperature $\left(55.8{ }^{\circ} \mathrm{C}\right)$ was trapped in timber solar heater boxes during the same duration.

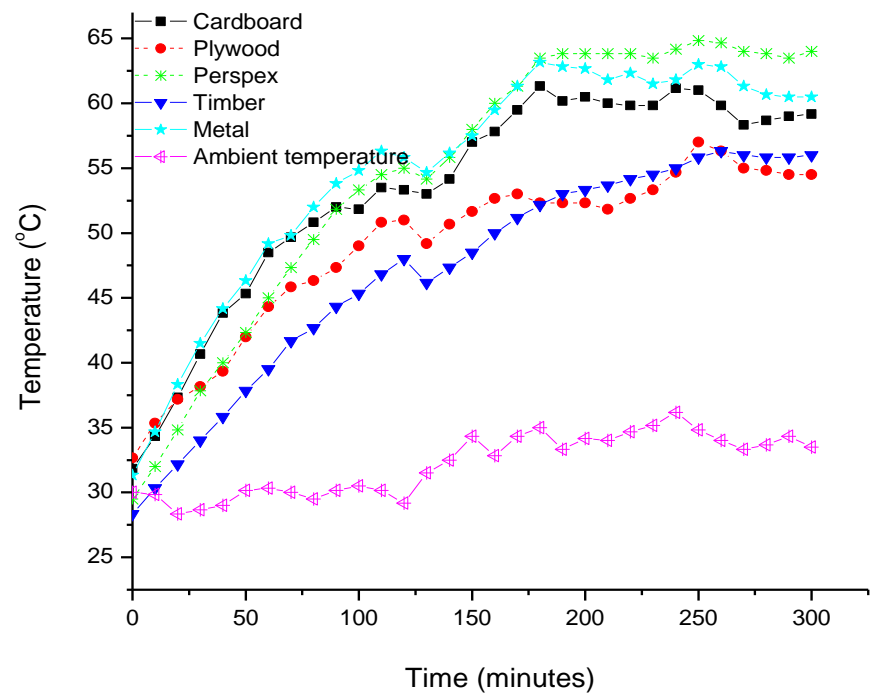

Fig 8: Temperature profiles inside adzuki bean seeds in solar heater boxes lined with aluminum foil combined with black paint

Cardboard solar heater boxes trapped 5.9\% and 3.2\% lower temperatures than Perspex and metal solar heater boxes, respectively. The temperatures trapped in plywood and timber solar heater boxes were 6.6 and 8.5\% lower than temperature trapped in cardboard solar heater boxes. The comparison of overall means for between and within seed temperatures trapped by solar heater boxes are presented in Table 1. The results showed no significant differences between cardboard, plywood, Perspex and timber boxes in between seed temperature trappings. Metal solar heater boxes trapped the maximum between seed mean temperature which was significantly $(\rho=0.015)$ different from means of all solar heater boxes, except Perspex.

The mean within seed temperatures of 54.0, 52.8, 52.3, and $50.0{ }^{\circ} \mathrm{C}$ were trapped in metal, cardboard, Perspex, and plywood, respectively, but were not significantly different from each other.

Table 1: Comparison of overall means for between and within seed temperatures trapped by the solar heater

\begin{tabular}{|l|l|l|}
\hline \multicolumn{2}{|c|}{ boxes } \\
\hline $\begin{array}{l}\text { Solar heater boxes } \\
\text { (Materials) }\end{array}$ & $\begin{array}{l}\text { Between seed } \\
\text { temperature }\left({ }^{\circ} \mathbf{C}\right)\end{array}$ & $\begin{array}{l}\text { Within seed } \\
\text { Temperature }\left({ }^{\circ} \mathbf{C}\right)\end{array}$ \\
\hline Cardboard & $50.4^{\mathrm{b}}$ & $52.8^{\mathrm{ab}}$ \\
\hline Plywood & $50.3^{\mathrm{b}}$ & $50.0^{\mathrm{bc}}$ \\
\hline Perspex & $51.2^{\mathrm{ab}}$ & $52.3^{\mathrm{ab}}$ \\
\hline Timber & $48.6^{\mathrm{b}}$ & $48.9^{\mathrm{c}}$ \\
\hline Metal & $53.5^{\mathrm{a}}$ & $54.0^{\mathrm{a}}$ \\
\hline
\end{tabular}

Means followed by different letters within the same column are significantly different $(\rho \leq 0.01)$

The lowest within seed temperature mean was obtained in timber solar heater boxes, which was significantly different from mean temperatures obtained in metal solar heater boxes.

Comparison of overall means for between and within seed temperatures due to differences in lining in the solar heater boxes are presented in Table 2. The results showed no significant differences in between seed temperature means trapped in solar heater boxes coated with aluminum foil and aluminum foil combined with black paint. However, both of these two linings were significantly higher $(\rho=0.01)$ than with the third lining or black paint. 
Table 2. Overall means for between and within seed temperatures obtained with the three different lining

\begin{tabular}{|l|l|l|}
\hline Lining materials & $\begin{array}{l}\text { Between seed } \\
\text { temperature }\left({ }^{\circ} \mathbf{C}\right)\end{array}$ & $\begin{array}{l}\text { Within seed } \\
\text { temperature }\left({ }^{\circ} \mathbf{C}\right)\end{array}$ \\
\hline Aluminum & $51.6^{\mathrm{a}}$ & $52.2^{\mathrm{a}}$ \\
\hline Black paint & $48.9^{\mathrm{b}}$ & $51.1^{\mathrm{a}}$ \\
\hline $\begin{array}{l}\text { Aluminum foil combined } \\
\text { With black paint }\end{array}$ & $51.9^{\mathrm{a}}$ & $51.5^{\mathrm{a}}$ \\
\hline
\end{tabular}

Means followed by different letters within the same column are significantly different $(\rho \leq 0.01)$

No significant differences were observed between means of within seed temperatures trapped in solar heater boxes coated with aluminum foil, black paint, or aluminum foil combined with black paint. However, it was generally observed that the combination of aluminum foil and black paint trapped more heat compared with the other two linings used separately. The interaction effect of the two main factors (ie. materials and linings) on between and within seed temperatures was significant $(\rho>0.05)$. Each one of the two factors, materials and linings, influenced the other with respect to their effect on temperature.

\subsection{Conclusion experiment 1}

Cardboard and plywood are considered as better materials compared to the others. They have better thermal diffusivity than that of Perspex and timber; moreover, they are cheaper and easy to handle. Cardboard and plywood boxes were respectively 53.3 and $52.2 \%$ cheaper than metal. The combination of the two linings had a better capacity in trapping solar energy compared to the linings used individually.

\subsection{Experiment 2. Effect of seed depth on temperatures trapped by solar heater boxes}

In this experiment only the cardboard and plywood solar heater boxes were used to evaluate the effect of seed depth (thickness of seed layer) on solar energy trapping capacity of the solar heater boxes. The between seed temperatures trapped in the cardboard and plywood solar heater boxes during two hours of exposure using 1, 3, 5, 7 and 9 kilograms of adzuki bean seeds are presented in Table 3.

The results showed that temperatures decreased with an increase in the thickness of adzuki beans seed layers inside both solar heater boxes. It was observed that in both solar heat boxes, the highest between seed temperatures were obtained with one kilogram of adzuki bean seeds or with the least thickness of the seed layer $(0.5 \mathrm{~cm})$. The average between seed temperatures trapped in plywood and cardboard solar heater boxes with one kilogram seeds were 73.3 and $72.0{ }^{\circ} \mathrm{C}$, respectively; these differences were not significantly different. However, when seed quantity was increased to three kilograms $(2.2 \mathrm{~cm}$ thick seed layer $)$ the between seed temperatures decreased to $66.0{ }^{\circ} \mathrm{C}$ in both solar heater boxes. With five kilograms of adzuki bean seeds $(3.0 \mathrm{~cm}$ thick seed layer) the between seed temperatures achieved were 58.2 and $56.0{ }^{\circ} \mathrm{C}$ in cardboard and plywood solar heater boxes, respectively.

Table 3: Between seed temperatures recorded during two hours of exposure in solar heater boxes in relation to seed depth

\begin{tabular}{|l|l|l|l|l|}
\hline \multicolumn{2}{|l|}{ Treatments } & \multicolumn{2}{|c|}{$\begin{array}{c}\text { Solar heater boxes } \\
\text { (materials) }\end{array}$} \\
\hline $\begin{array}{l}\text { Weight } \\
(\mathbf{k g})\end{array}$ & $\begin{array}{l}\text { Thickness of } \\
\text { seed layer }(\mathbf{c m})\end{array}$ & $\begin{array}{l}\text { Weight/area } \\
\left(\mathrm{g} / \mathbf{c m}^{2}\right)\end{array}$ & \multicolumn{2}{|c|}{ Temperatures $\left({ }^{\circ} \mathrm{C}\right)$} \\
\cline { 3 - 5 } & & 0.7 & $73.3^{\mathrm{a}}$ & $72.0^{\mathrm{a}}$ \\
\hline 1 & 0.5 & 2.1 & $66.0^{\mathrm{b}}$ & $66.0^{\mathrm{b}}$ \\
3 & 2.2 & 3.5 & $56.0^{\mathrm{c}}$ & $58.2^{\mathrm{c}}$ \\
5 & 3.0 & 4.9 & $46.8^{\mathrm{d}}$ & $53.3^{\mathrm{c}}$ \\
7 & 4.3 & 6.3 & $36.0^{\mathrm{e}}$ & $40.4^{\mathrm{e}}$ \\
9 & 6.5 & & & \\
\hline
\end{tabular}

* Average of six replications.

Means within columns followed by same letters are not significantly different $(\rho \geq 0.05)$

No significant differences were observed between the temperatures trapped by the solar heater boxes with five kilograms of adzuki bean seed, however, significant differences were observed between the temperatures trapped by the solar heater boxes when seven kilograms of adzuki bean seeds were used. Between seed temperatures achieved with seven kilograms seed $\left(4.3 \mathrm{~cm}\right.$ thick seed layer) were, 53.3 and $46.8{ }^{\circ} \mathrm{C}$ in cardboard solar heater boxes and plywood solar heater boxes, respectively. With nine kilograms of seeds, the 
temperatures trapped by the solar heater boxes were decreased to 40.4 and $36.0{ }^{\circ} \mathrm{C}$ in cardboard and plywood solar heater boxes, respectively.

Significant differences in between seed temperatures trapped in plywood solar heater boxes were observed for different thickness of seed layers used. However, no significant differences in seed temperatures were observed between five and seven kilograms seeds in cardboard solar heater boxes. The results showed that differences in between seed temperatures due to seed layer thickness was highly significant $(\rho<0.0001)$. Moreover, the two materials used (cardboard and plywood) also showed significant $(\rho=0.013)$ differences in their effect on between seed temperatures. The interaction between the two factors, material and seed thickness, was significant $(\rho=0.05)$.

It was observed that temperatures decreased with increase in seed layer thickness of adzuki beans. This might be due to the fact that more time was needed for temperature increases with thick layer of seeds. Yoshida et al, (1983) explained that, thick layers of beans inside solar heater boxes needed a longer time to raise the temperatures, and do not reach very high temperatures; however, they retain the temperatures attained for a longer time. With thin layers of seeds, the temperature increases fast, but the heat is lost rapidly. The results of the study showed that solar heater boxes trapped temperatures $66.5,61.0$, and $52.5{ }^{\circ} \mathrm{C}$ with seed layer thicknesses of 1.5, 3.0, and $4.5 \mathrm{~cm}$, respectively. These results were nearly similar in both solar heater boxes in this study. The slight differences was due to minor differences in size and the materials of solar heater boxes used, which consisted of $2 \mathrm{~mm}$ thick plastic measuring $11.5 \mathrm{~cm}$ square and $4.5 \mathrm{~cm}$ deep.

The temperature achieved with seven kilograms seeds inside cardboard solar heater boxes was higher than that of plywood solar heater boxes which achieved $46.8^{\circ} \mathrm{C}$. This is attributed to the higher thermal diffusivity of cardboard than that of plywood, which implies more propagation and fast diffusion of heat into cardboard solar heater boxes. The temperatures achieved were suitable for heat treatment of stored-product insects. According to Beckett et al. (2007) the temperatures for effective structural heat treatment should be $\geq 50$ ${ }^{\circ} \mathrm{C}$ for at least 24 hours or more of exposure.

\subsection{Conclusion experiment 2}

Cardboard solar heater boxes were better than plywood solar heater boxes in retaining heat, especially with increased seed layer thickness, due to its thermal diffusivity. The mean temperature achieved with seven kilograms of adzuki bean seeds in cardboard solar heater boxes was $53.3{ }^{\circ} \mathrm{C}$ during two hours of exposure.

\section{General conclusion}

Cardboard and plywood seem to be the more suitable materials to be used for solar heater boxes to control $C$. maculatus due to their thermal properties and also as they are relatively cheaper as compared to other materials. Cardboard and plywood solar heater boxes are cheaper than Perspex, metal, and timber. Aluminum foils combined with black paint was the best lining materials to retain heat inside the solar heater boxes. It was also shown the cardboard solar heater box is better than plywood in retaining heat with larger amounts of seeds (due to its thermal diffusivity). Mean temperatures achieved with seven kilograms of adzuki bean seeds in cardboard solar heater boxes was $13.9 \%$ higher than temperatures trapped in plywood solar heater boxes.

\section{Acknowledgment}

The authors would like to acknowledge the Department of Plant Protection, Faculty of Agriculture, University Putra Malaysia for sponsoring the research.

\section{References}

[1]. Amin, N., Lung, C.W., and Sopian, K. (2009). A practical field study of various solar cells on their performance in Malaysia Renewable Energy, 34(8), 1939-1946.

[2]. Banks, H.J. (1998). Prospects for heat disinfestation .Stored grain Research laboratory, CSIRO Entomology, Canberra

[3]. Beckett, S.J, Fields, P.G, and Subramanyam, BH. (2007). Disinfestation of stored products and associated structures using heat. In Tang, E. M. J., Wang, S. and Lurie, S. (Ed.), Heat treatment for postharvest pest control. Reading: CABI.

[4]. Chauhan, Y. S., and Ghaffar, M. A. (2002). Solar heating of seeds-a low cost method to control bruchid (Callosobruchus spp.) attack during storage of pigeonpea. Journal of Stored Products Research, 38(1), 87-91.

[5]. Kitch, L. W., Ntoukam, G., Shade, R. E., Wolfson, J. L., and Murdock, L. L. (1992). A solar heater for disinfesting stored cowpeas on subsistence farms. Journal of Stored Products Research, 28(4), 261-267.

[6]. Mekasha.C., Dzolkifli, O., Yusuf, S., Rita, M., and Noorma, O. (2006). Development of efficient solar heaters for storage insect pest management. African Crop Science Journal, 14(3), 253-261.

[7]. Murdock, L. L., and Shade, R. E. (1991). Eradication of cowpea weevil (Coleoptera: Bruchidae) in cowpeas by solar heating. American Entomologist, 37(4), 228-231.

[8]. Ntoukam, G., Kitch, L. W., Shade, R. E., and Murdock, L. L. (1997). A novel method for conserving cowpea germplasm and breeding stocks using solar disinfestation. Journal of Stored Products Research, 33(2), 175-179.

[9]. Qaisrani, R., and Banks, J. (2000). The prospects for heat disinfestation of grain. Paper presented at the Australian Postharvest Technical Conference.

[10]. Solangi, K. H., Islam, M. R., Saidur, R., Rahim, N. A., andFayaz, H. (2011). A review on global solar energy policy. Renewable and Sustainable Energy Reviews, 15(4), 2149-2163.

[11]. Yoshida, H. Yoshida, T., and Gichuki, E. M. (1983). Use of solar heat to control stored-product insect pests: bean depth. Sci. Rep. Fac. Agrie. Okayama Univ, 61, 5-8. 